\title{
Does Extracorporeal Membrane Oxygenation Improve Survival in Pediatric Acute Respiratory Failure?
}

\begin{abstract}
Ryan P. Barbaro ${ }^{1,2}$, Yuejia Xu ${ }^{3}$, Santiago Borasino ${ }^{4}$, Edward J. Truemper ${ }^{5}$, R. Scott Watson ${ }^{6,7}$, Ravi R. Thiagarajan ${ }^{8}$, David Wypij ${ }^{3,8}$, and Martha A. Q. Curley ${ }^{9,10,11}$; for the RESTORE Study Investigators*

${ }^{1}$ Department of Pediatrics and ${ }^{2}$ Child Health Evaluation and Research Center, University of Michigan, Ann Arbor, Michigan; ${ }^{3}$ Department of Biostatistics, Harvard T. H. Chan School of Public Health, Boston, Massachusetts; ${ }^{4}$ Department of Pediatrics, University of Alabama, Birmingham, Alabama; ${ }^{5}$ Department of Pediatrics, Children's Hospital and Medical Center of Nebraska, Omaha, Nebraska; ${ }^{6}$ Department of Pediatrics, University of Washington School of Medicine, Seattle, Washington; ${ }^{7}$ Center for Child Health, Behavior, and Development, Seattle Children's Research Institute, Seattle, Washington; ${ }^{8}$ Department of Cardiology, Boston Children's Hospital, Boston, Massachusetts; ${ }^{9}$ The Children's Hospital of Philadelphia Research Institute, Philadelphia, Pennsylvania; and ${ }^{10}$ Department of Family and Community Health, School of Nursing, and ${ }^{11}$ Department of Anesthesia and Critical Care, Perelman School of Medicine, University of Pennsylvania, Philadelphia, Pennsylvania
\end{abstract}

ORCID IDs: 0000-0002-3645-0359 (R.P.B.); 0000-0001-5228-6694 (M.A.Q.C.).

\section{Abstract}

Rationale: Extracorporeal membrane oxygenation (ECMO) has supported gas exchange in children with severe respiratory failure for more than 40 years, without ECMO efficacy studies.

Objectives: To compare the mortality and functional status of children with severe acute respiratory failure supported with and without ECMO.

Methods: This cohort study compared ECMO-supported children to pair-matched non-ECMO-supported control subjects with severe acute respiratory distress syndrome (ARDS). Both individual case matching and propensity score matching were used. The study sample was selected from children enrolled in the clusterrandomized RESTORE (Randomized Evaluation of Sedation Titration for Respiratory Failure) clinical trial. Detailed demographic and daily physiologic data were used to match patients. The primary endpoint was in-hospital mortality. Secondary outcomes included hospital-free days, ventilator-free days, and change in functional status at hospital discharge.
Measurements and Main Results: Of 2,449 children in the RESTORE trial, 879 (35.9\%) non-ECMO-supported patients with severe ARDS were eligible to match to 61 (2.5\%) ECMO-supported children. When individual case matching was used (60 matched pairs), the in-hospital mortality rate at 90 days was $25 \%$ ( 15 of 60 ) for both the ECMO-supported and non-ECMO-supported children $(P>0.99)$. With propensity score matching (61 matched pairs), the ECMO-supported in-hospital mortality rate was 15 of 61 (25\%), and the non-ECMO-supported hospital mortality rate was 18 of $61(30 \%)$ $(P=0.70)$. There was no difference between ECMO-supported and non-ECMO-supported patients in any secondary outcomes.

Conclusions: In children with severe ARDS, our results do not demonstrate that ECMO-supported children have superior outcomes compared with non-ECMO-supported children. Definitive answers will require a rigorous multisite randomized controlled trial.

Keywords: extracorporeal membrane oxygenation; pediatric acute respiratory distress syndrome; acute respiratory distress syndrome; extracorporeal life support; propensity score analysis

(Received in original form September 20, 2017; accepted in final form January 26, 2018)

*The RESTORE (Randomized Evaluation of Sedation Titration for Respiratory Failure) study investigators are listed in the online supplement.

Supported by grants from the NHLBI and the National Institute of Nursing Research, NIH (U01 HL086622 [M.A.Q.C.] and U01 HL086649 [D.W.]).

Author Contributions: All authors fulfill authorship criteria through substantial contributions to conception or design of the study; acquisition, analysis, or interpretation of the data; and manuscript drafting or critical revision of the manuscript for important intellectual content. M.A.Q.C. and D.W. had full access to all of the data and take responsibility for data integrity and analytic accuracy.

Correspondence and requests for reprints should be addressed to Ryan P. Barbaro, M.D., M.S., University of Michigan, 1500 East Medical Center Drive, Mott F-6790/Box 5243, Ann Arbor, Ml 48109. E-mail: barbaror@med.umich.edu.

This article has an online supplement, which is accessible from this issue's table of contents at www.atsjournals.org.

Am J Respir Crit Care Med Vol 197, Iss 9, pp 1177-1186, May 1, 2018

Copyright $\odot 2018$ by the American Thoracic Society

Originally Published in Press as DOI: 10.1164/rccm.201709-18930C on January 26, 2018

Internet address: www.atsjournals.org 


\section{At a Glance Commentary}

\section{Scientific Knowledge on the}

Subject: Despite an average mortality rate of $40 \%$ and a median hospitalization cost of $\$ 230,000$, no clinical trials have investigated extracorporeal membrane oxygenation (ECMO) support for respiratory failure in nonneonatal children. We aimed to address this knowledge gap in a pairmatched cohort study.

\section{What This Study Adds to the}

Field: In this pair-matched cohort study, we found no difference between children supported with or without ECMO for in-hospital mortality, hospital-free days, ICU-free days, mechanical ventilator-free days, or change in overall or cerebral functional status at hospital discharge. These results, in conjunction with the associated cost and risk of ECMO, support the consideration of performing a randomized controlled trial of ECMO support in pediatric respiratory failure.

Since the 1970s, extracorporeal membrane oxygenation (ECMO) support has been used to support gas exchange for children with severe acute respiratory failure who fail mechanical ventilation (1). Currently, approximately 1,500 U.S. children and 3,000 children worldwide receive ECMO support each year $(2,3)$. For comparison, this is similar to the annual number of pediatric bone marrow transplants $(1,816)$ and the combined annual total of pediatric liver, heart, and kidney transplants $(1,758)$ in the United States (4-7). ECMO, with a median hospitalization cost of $\$ 230,000$, is more expensive than each of these other procedures (7).

Since 1974, eight randomized controlled trials have been reported in ECMO for respiratory failure, and none have included nonneonatal pediatric patients (8-15). Cochrane systematic reviews of this evidence concluded that ECMO for neonatal respiratory failure had a survival advantage (16), but there was insufficient evidence to demonstrate a survival advantage for ECMO used to support respiratory failure in adults (17). Moreover, these trials were performed before 2009; since then, advances in ECMO technology have enhanced the delivery of ECMO support $(18,19)$, and new research has changed conventional management of severe acute respiratory distress syndrome (ARDS) (20-23).

ECMO is now an established, prevalent, and expensive life-support technology, with no nonneonatal pediatric trials and conflicting neonatal and adult evidence $(2,16,17,24)$. The prospectively collected, high-quality data from the multicenter randomized controlled trial RESTORE (Randomized Evaluation of Sedation Titration for Respiratory Failure) offers a compelling opportunity to address this evidence gap (25). The primary aim of our reexamination of the RESTORE study data is to determine if pediatric ECMOsupported patients have a lower in-hospital mortality rate than a pair-matched cohort of non-ECMO-supported pediatric patients with ARDS. Our secondary aims are to compare hospital-, pediatric ICU (PICU)-, and ventilator-free days as well as the change in overall and cerebral functional status at hospital discharge.

\section{Methods}

This is a pair-matched cohort study using data from the multicenter randomized controlled RESTORE clinical trial, performed from 2009 to 2013 at 31 U.S. PICUs (25). RESTORE enrolled 2,449 children, aged 2 weeks to 17 years, who were receiving invasive mechanical ventilator support for acute respiratory failure. Each participating institution obtained institutional review board approval and informed consent from the legal guardian of participating patients. Patients were cluster randomized by the PICU to receive usual care or protocolized targeted sedation, with a primary endpoint of mechanical ventilation duration and secondary outcomes including overall functional status, cerebral functional status, and in-hospital mortality. The decision to place a patient on ECMO and the ECMO care delivery during ECMO support was at the discretion of the treating medical team, as was the nonsedation care delivery among non-ECMO-supported patients $(25,26)$. Because respiratory supportive care was not protocolized in the RESTORE study, there was likely variability in respiratory care within the ECMO-supported and within the non-ECMO-supported groups. The study protocol and findings have been described elsewhere (25).

The RESTORE clinical trial database contains admission diagnosis and Pediatric Risk of Mortality from the first 12 hours in the PICU (PRISM III-12) scores, daily assessments of study patients' mechanical respiratory support, mean airway pressure, $\mathrm{FI}_{\mathrm{O}_{2}}, \mathrm{~Pa}_{\mathrm{O}_{2}}$ (if arterial specimen available), pulse oximeter-measured oxyhemoglobin saturation, and organ dysfunction scores. In ECMO-supported patients, these same measures were also recorded within 6 hours before the start of ECMO support, as was the ECMO cannulation strategy (venoarterial or venovenous), the type of membrane oxygenator and mechanical blood pump, and the ECMO blood flow rates. We imputed oxygenation index (OI) data in children who were urgently cannulated for ECMO support and missing OI.

$\mathrm{OI}=\frac{\left(\mathrm{F}_{\mathrm{O}_{2}} \times \text { mean airway pressure }\left[\mathrm{cm} \mathrm{H} \mathrm{H}_{2} \mathrm{O}\right]\right)}{\mathrm{Pa}_{\mathrm{O}_{2}}[\mathrm{~mm} \mathrm{Hg}]} \times 100$

\section{Patient Selection}

In the current study, patients were eligible to be considered in the ECMO-supported patient group if the patient received ECMO support within 15 days from the start of mechanical ventilation (27). Among non-ECMO-supported patients, we excluded patients not considered to be ECMO candidates. This included patients who had received bone marrow transplantation and patients in a vegetative state or in a coma at admission, as measured by Pediatric Overall Performance Category (POPC) of 5 or greater (28). Remaining non-ECMOsupported patients were eligible for matching at any time during the first 15 days of mechanical ventilation. To be eligible, on the day of matching, non-ECMO-supported patients needed to be mechanically ventilated, on an $\mathrm{FI}_{\mathrm{O}_{2}}$ of at least 0.60 , and meet Pediatric Acute Lung Injury Consensus Conference guidelines for severe pediatric ARDS (PARDS) oxygenation criteria $(\mathrm{OI} \geqslant 16)(29)$.

\section{Outcome}

The primary outcome was 90-day inhospital mortality. Secondary outcomes included 90-day hospital-free days, PICUfree days, and ventilator-free days. Among survivors, we compared the change in overall and cerebral functional status by measuring the change in POPC and 
Pediatric Cerebral Performance Category (PCPC) from admission to discharge (28).

In RESTORE, two-thirds of surviving children were randomly sampled for a 6-month telephone follow-up after hospital discharge. Among sampled patients, we assessed their need for home oxygen and hospital readmission within 6 months after hospital discharge.

\section{Statistical Analysis}

Before matching, characteristics of ECMOsupported and eligible non-ECMOsupported patients were compared using generalized estimating equations accounting for PICU as a cluster variable. Then, pair-matched cohort analyses were performed using individual case matching and propensity score matching on the basis of variables expected to be associated with the use of ECMO, similar to previously published studies $(30,31)$. In both approaches, 1:1 matching without replacement was made on a daily observation basis. ECMO-supported subjects contributed a single observation on their first ECMO day; non-ECMOsupported subjects could have multiple eligible days for matching, and each patient-day combination was considered separately. Comparisons of characteristics and outcomes of matched pairs after matching were based on exact sign tests and exact $95 \%$ confidence intervals for the median of the paired differences for continuous and ordinal variables and exact conditional maximum likelihood estimation for binary variables.

For individual case matching, ECMOsupported patients were matched with non-ECMO-supported patients according to OI group ( $<20.0,20.0-29.9,30.0-39.9$, or $\geqslant 40.0$ ), days of mechanical ventilation $( \pm 2 \mathrm{~d})$, primary diagnosis group (aspiration pneumonia, bronchiolitis, or asthma; pneumonia; sepsis; or other), and age category at PICU admission (2 wk-1.99 yr, 2.00-5.99 yr, or 6.00-17.99 yr). When multiple non-ECMO-supported observations could be matched to an ECMO-supported observation, the non-ECMO-supported observation with the closest OI value and days of mechanical ventilation was selected as the best match.

For propensity score matching, multivariable logistic regression was used to estimate the probability of receiving ECMO treatment for each observation (patient-day). Covariates included continuous OI, days of mechanical ventilation, primary diagnosis group, continuous age in years at PICU admission, number of organ dysfunctions on Day 0 or 1 , dichotomized $\mathrm{FI}_{\mathrm{O}_{2}}(<100 \%$ or $100 \%)$, and prior use of high-frequency oscillatory ventilation (HFOV). OI and days of mechanical ventilation were modeled via generalized additive model terms because of nonlinear effects. Each ECMO-supported observation was matched with a non-ECMOsupported observation with the smallest absolute difference in the propensity scores (fitted probabilities).

Additional sensitivity analyses were conducted to confirm whether extreme or imputed OI values affected our findings. For this, we restricted the analysis to ECMOsupported observations whose OI calculation did not involve imputation and was greater than 15, and non-ECMO-supported observations with OI less than 109. Statistical analyses were performed with SAS software, version 9.4 (SAS Institute Inc.) using twosided $\alpha=0.05$ level tests.

\section{Results}

Sixty-one patients received ECMO at 21 of 31 RESTORE participating PICUs (68\%). No ECMO-supported patients were excluded from the analysis, because all were placed on ECMO by Day 15. Among the 21 RESTORE centers that performed ECMO, their total annual ECMO volumes ranged from 2 to 77 and were greater than 10 at 18 of 21 centers $(86 \%)$. The ECMO cannulation strategy was venovenous in 38 of 61 cases (62\%). Of the 2,388 non-ECMO-supported children, $879(36.8 \%)$ met inclusion criteria, $121(13.8 \%)$ of whom were cared for at one of 10 PICUs (32\%) that did not place any RESTORE patients on ECMO (Figure 1).

Before matching, there were no differences between ECMO-supported and non-ECMO-supported patients in age, primary diagnoses, and past medical histories (Table 1). ECMO-supported children were more often girls, had better baseline POPC and PCPC, higher admission risk of mortality, more organ systems in failure, and higher use of HFOV.

The individual case-matching technique produced 60 matched pairs, and the propensity score-matching technique produced 61 matched pairs. After matching, covariate balance was improved for matched variables (Table 2). ECMO-supported children had slightly longer length of mechanical ventilation and were more likely to have $\mathrm{FI}_{\mathrm{O}_{2}}$ of $100 \%$ on the day of matching than individual case-matched children. Propensity score matching resulted in wellbalanced covariates for all matched variables.

\section{Outcomes}

The 90-day hospital mortality rate for individual case-matched patients was 25\% for both ECMO-supported and non-ECMO-supported patients $(P>0.99)$. In propensity score-matched children, the hospital mortality rate was $25 \%$ for ECMOsupported versus $30 \%$ for non-ECMOsupported patients $(P=0.70)$ (Table 3$)$.

In the individual case- and propensity score-matched patients, 90-day hospital-, PICU-, and ventilator-free days were also not different from the ECMO-supported patients (Table 3 ). In the propensity score-matched patients, 90-day hospitalfree days were 35 days (interquartile range [IQR], 0-59 days) for the ECMO-supported versus 54 days (0-72 days) for the non-ECMO-supported patients $(P=0.06)$. In a post hoc analysis, limited to survivors with matched pairs, there was a difference in the PICU and hospital length of stay. Among the 31 propensity-matched surviving pairs, the PICU length of stay was longer in ECMO-supported survivors (median [IQR], $29 \mathrm{~d}$ [18-47 d]) than in non-ECMO-supported survivors (20 $\mathrm{d}[9-26 \mathrm{~d}] ; P=0.03)$, and similarly the hospital length of stay was longer among ECMO-supported survivors (40 d [28-62 d]) versus non-ECMO-supported survivors (23 d [13-36 d]; $P=0.01$ ).

Among survivors in the individual case- and propensity score-matched patients, the changes from baseline to discharge POPC and PCPC were not different between ECMO- and non-ECMOsupported groups (Table 3).

At the 6-month telephone follow-up, 21 of the 46 surviving ECMO-supported children and 19 of the 43 surviving non-ECMO-supported propensity score-matched children participated in the follow-up. Two (9\%) ECMO-supported and three (16\%) non-ECMO-supported children had a new home oxygen requirement after hospital discharge. Nine (43\%) ECMO-supported and eight (42\%) nonECMO-supported children had required at least one hospitalization within 6 months after discharge.

After excluding eight cases with imputed data, 53 ECMO-supported patients 


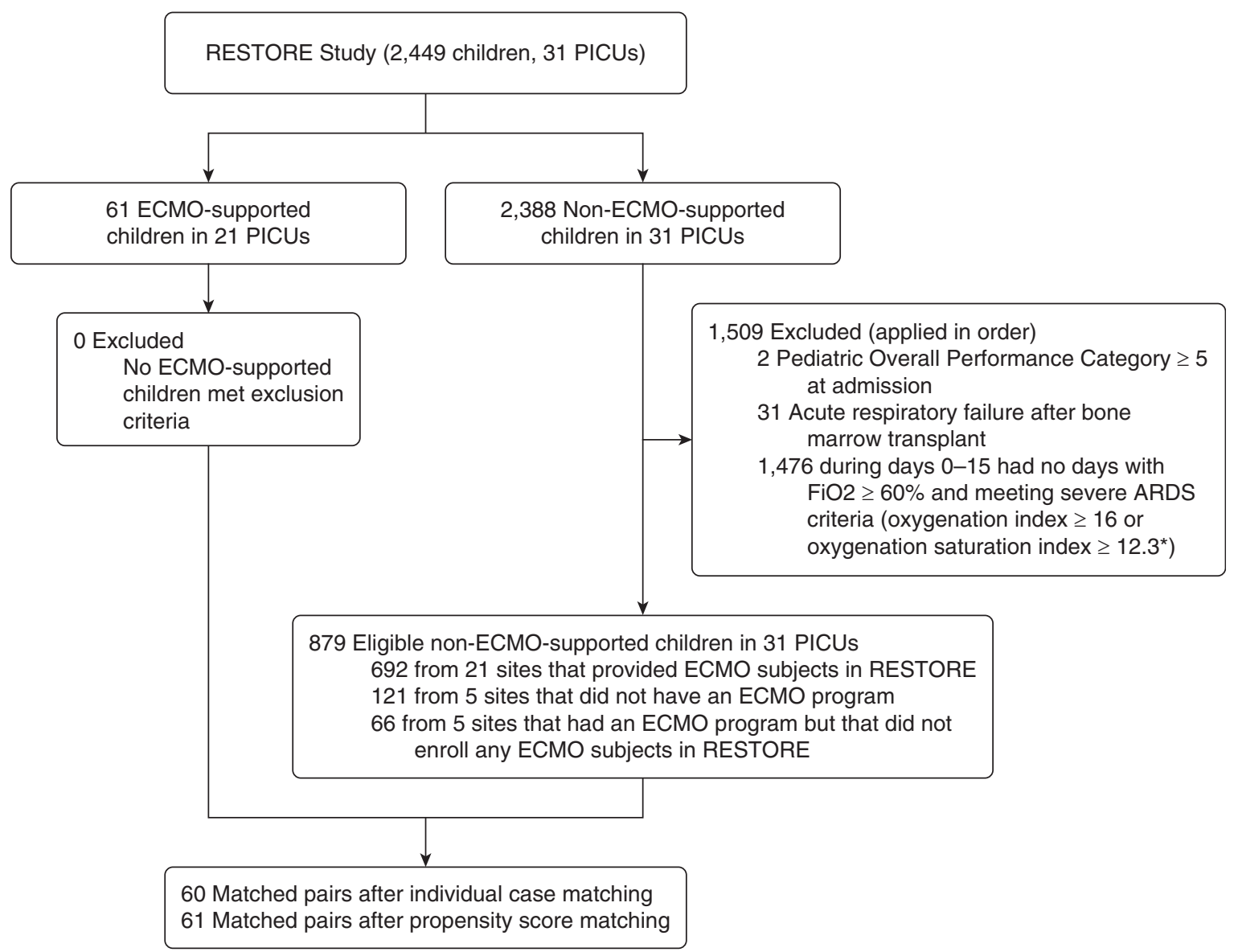

Figure 1. Flow diagram for exclusions and matching. ${ }^{*}$ Oxygenation index was calculated as $\left(\mathrm{Fl}_{\mathrm{O}_{2}} \times\right.$ mean airway pressure)/PaO $\mathrm{O}_{2} \times 100$. When an arterial blood gas measurement was not available, oxygen saturation as measured by pulse oximetry $\left(\mathrm{Sp}_{\mathrm{O}_{2}}\right)$ was used to estimate $\mathrm{Pa} \mathrm{O}_{2}$ to calculate the oxygenation saturation index $\left[\left(\mathrm{Fl}_{\mathrm{O}_{2}} \times\right.\right.$ mean airway pressure $\left.) / \mathrm{Sp}_{\mathrm{O}_{2}} \times 100\right]$. Lower scores reflect better oxygenation. ARDS $=$ acute respiratory distress syndrome; ECMO = extracorporeal membrane oxygenation; PICU = pediatric ICU; RESTORE = Randomized Evaluation of Sedation Titration for Respiratory Failure.

were available for matching in the sensitivity analyses. Individual case matching yielded 52 matches and propensity score yielded 53 matches, with similar balancing of covariates (see Table E1 in the online supplement) and similar primary and secondary outcomes (Table E2).

\section{Discussion}

In this cohort study of 122 matched children with severe acute respiratory failure supported with and without ECMO, we found no difference in the in-hospital mortality, no difference in the change in overall or cerebral functional status, and no difference in hospital-, PICU-, or ventilatorfree days. To our knowledge, this is the first study in pediatric acute respiratory failure to compare the change in functional outcomes among a matched cohort of ECMOsupported and non-ECMO-supported patients. Our findings were consistent across two separate matching techniques and were robust to a priori sensitivity analysis that restricted data to those without imputed covariates.

There are no clinical trials comparing ECMO support to conventional mechanical ventilation support in PARDS (32). Our study attempts to address the gap in ECMO efficacy research by reanalyzing the rigorously collected data from the RESTORE clinical trial. The 879 nonECMO-supported children with severe ARDS offered a large sample to make wellbalanced matches without replacement (30). We applied these reliable and detailed data to match patients with similar severity of respiratory failure and at similar time points in the course of their illness in a design similar to the approach taken in a study of adult patients (31).

For a matched cohort study among ECMO-supported patients and nonECMO-supported patients to be feasible, it needs to be plausible that a similar patient might be placed on ECMO by one provider and not by another. In our study, there is sufficient variability between and within centers in patient selection for ECMO to enable this comparison. First, 121 patients were treated at hospitals that did not offer ECMO. Consequently, those patients were less likely to receive ECMO support for severe acute respiratory failure. Second, among ECMO-supported children, the OI at ECMO initiation, use of HFOV, and days of mechanical ventilation varied greatly, which suggests clinicians have different thresholds for deciding to provide ECMO support. Third, a recently published 
Table 1. Characteristics of Extracorporeal Membrane Oxygenation-supported and Eligible Non-Extracorporeal Membrane Oxygenation-supported Patients

\section{Characteristics}

Age at PICU admission, yr, median (IQR)

$$
\begin{aligned}
& n(\%) \\
& 2 \mathrm{wk}-1.99 \mathrm{yr} \\
& 2.00-5.99 \mathrm{yr} \\
& 6.00-17.99 \mathrm{yr}
\end{aligned}
$$

Female, $n(\%)$

Non-Hispanic white, $n /$ total $(\%)$

Baseline PCPC score, $n(\%)$

Normal $(\mathrm{PCPC}=1)$

Mild disability $(P C P C=2)$

Moderate disability $(\mathrm{PCPC}=3)$

Severe disability $(\mathrm{PCPC}=4)$

Baseline POPC score, $n(\%)$

Good overall performance $(P O P C=1)$

Mild overall disability $(\mathrm{POPC}=2$ )

Moderate overall disability $(\mathrm{POPC}=3)$

Severe overall disability $(\mathrm{POPC}=4)$

PRISM III-12 score, median (IQR)

Risk of mortality based on PRISM III-12 score, median (IQR)

Primary diagnosis, $n(\%)$

Aspiration pneumonia, bronchiolitis, asthma

Pneumonia

Sepsis

Other $^{\dagger}$

Number of organ dysfunctions on Day 0 or 1 , median (IQR)

PARDS based on worst OI or OSI on Day 0 or 1 , $n(\%)^{\ddagger}$

At risk $(\mathrm{OI}<4.0$ or $\mathrm{OSI}<5.0)$

Mild $(\mathrm{OI}=4.0-7.9$ or $\mathrm{OSI}=5.0-7.4)$

Moderate $(\mathrm{OI}=8.0-16.0$ or $\mathrm{OSI}=7.5-12.3)$

Severe $(\mathrm{OI}>16.0$ or $\mathrm{OSI}>12.3)$

Any past medical history, $n(\%)$

Prematurity ( $<36$ wk postmenstrual age)

Asthma (prescribed bronchodilators or steroids)

Seizure disorder (prescribed anticonvulsants)

Neurologic/neuromuscular disorder putting patient at risk of aspiration

Cancer (current or previous diagnosis)

Known chromosomal abnormality

Hospital course characteristics, $n(\%)$

Sedation protocol group (vs. usual care)

Ever used HFOV

\section{ECMO $(n=61)$}

Non-ECMO Severe ARDS $(n=879)$

$P$ Value*

$4.2(0.8-12.0)$
$22(36)$
$11(18)$
$28(46)$
$39(64)$
$30 / 57(53)$
$55(90)$
$1(2)$
$4(7)$
$1(2)$
$52(85)$
$4(7)$
$4(7)$
$1(2)$
$12(4-21)$
$13.1(1.7-42.6)$

$15(25)$
$28(46)$
$14(23)$
$4(7)$
$3(2-4)$

$3(2-4)$

$.1(0.8-10.7)$

0.40

0.28

346 (39)

182 (21)

351 (40)

467/872 (54)
$0(0)$

0 (0)

4 (7)

57 (93)

8 (13)

7 (11)

3 (5)

1 (2)

8 (13)

2 (3)

29 (48)
426 (48)

619 (70)

81 (9)

86 (10)

93 (11)

567 (65)

108 (12)

99 (11)

105 (12)

9 (4-15)

$4.9(1.5-19.6)$

0.20

0.04

0.45

275 (31)

359 (41)

154 (18)

91 (10)

$2(1-3)$

$<0.001$

0.05

$<0.001$

$<0.001$

0.002

14 (2)

33 (4)

87 (10)

745 (85)

142 (16)

131 (15)

94 (11)

0.60

74 (8)

0.46

0.10

93 (11)

0.10

55 (6)

0.60

0.28

446 (51)

262 (30)
0.72 $<0.001$

Definition of abbreviations: ARDS = acute respiratory distress syndrome; ECMO = extracorporeal membrane oxygenation; HFOV = high-frequency oscillatory ventilation; IQR = interquartile range; OI= oxygenation index; OSI = oxygen saturation index; PARDS = pediatric acute respiratory distress syndrome; PCPC = Pediatric Cerebral Performance Category; PICU = pediatric ICU; POPC = Pediatric Overall Performance Category; PRISM III-12 = Pediatric Risk of Mortality III score from first $12 \mathrm{~h}$ in the PICU; $\mathrm{Sp}_{\mathrm{O}_{2}}=$ oxygen saturation as measured by pulse oximetry.

${ }^{*} P$ values for comparison between groups were calculated using linear, cumulative logit, logistic, and multinomial regression accounting for PICU as a cluster variable using generalized estimating equations for log-transformed continuous, ordinal, binary, and nominal variables, respectively.

${ }^{\dagger}$ Other primary diagnoses include acute chest syndrome/sickle cell disease, acute respiratory failure related to multiple blood transfusions, chemical pneumonitis, chronic lung disease, laryngotracheobronchitis, pertussis, pneumothorax (nontrauma), pulmonary edema, pulmonary embolus, pulmonary hemorrhage, pulmonary hypertension (not primary), and thoracic trauma.

${ }^{\ddagger} \mathrm{Ol}$ was calculated as $\left(\mathrm{Fl}_{\mathrm{O}_{2}} \times\right.$ mean airway pressure $) / \mathrm{Pa}_{\mathrm{O}_{2}} \times 100$. When an arterial blood gas measurement was not available, $\mathrm{Sp}_{\mathrm{O}_{2}}$ was used to estimate $\mathrm{Pa}_{\mathrm{O}_{2}}$ in order to calculate $\mathrm{OSI}\left[\left(\mathrm{FI}_{\mathrm{O}_{2}} \times\right.\right.$ mean airway pressure $\left.) / \mathrm{Sp}_{\mathrm{O}_{2}} \times 100\right]$. Lower scores reflect better oxygenation.

survey found no consensus on which patients were ECMO candidates (33).

One significant limitation to our findings is power. With only 61 patients receiving ECMO, we are not adequately powered to detect small differences in mortality that would be considered clinically significant. In the primary propensity score-matched analysis we found a 5\% lower mortality rate in ECMO-supported patients, and in the sensitivity propensity score-matched analysis there was a $10 \%$ lower in-hospital mortality for ECMOsupported patients, but in both cases this difference was not statistically significant. 
Table 2. Characteristics of Extracorporeal Membrane Oxygenation-supported and Eligible Non-Extracorporeal Membrane Oxygenation-supported Patients after Matching

\begin{tabular}{|c|c|c|c|c|c|c|}
\hline \multirow[b]{2}{*}{ Characteristics } & \multicolumn{3}{|c|}{ Individual Matching } & \multicolumn{3}{|c|}{ Propensity Score Matching } \\
\hline & $\begin{array}{l}\text { ECMO } \\
(n=60)\end{array}$ & $\begin{array}{l}\text { Non-ECMO } \\
(n=60)\end{array}$ & $\begin{array}{c}\text { Exact } \\
P \text { Value* }\end{array}$ & $\begin{array}{l}\text { ECMO } \\
(n=61)\end{array}$ & $\begin{array}{c}\text { Non-ECMO } \\
(n=61)\end{array}$ & $\begin{array}{c}\text { Exact } \\
P \text { Value* }\end{array}$ \\
\hline $\begin{array}{l}\text { Age at PICU admission, yr, median (IQR) } \\
n(\%)\end{array}$ & $4.4(0.8-12.1)$ & $5.0(0.9-13.3)$ & $\begin{array}{r}0.90 \\
>0.99\end{array}$ & $4.2(0.8-12.0)$ & $4.9(1.1-12.6)$ & $\begin{array}{r}0.80 \\
>0.99\end{array}$ \\
\hline $\begin{array}{l}2 \mathrm{wk}-1.99 \mathrm{yr} \\
2.00-5.99 \mathrm{yr} \\
6.00-17.99 \mathrm{yr}\end{array}$ & $\begin{array}{l}22(37) \\
10(17) \\
28(47)\end{array}$ & $\begin{array}{l}22(37) \\
10(17) \\
28(47)\end{array}$ & & $\begin{array}{l}22(36) \\
11(18) \\
28(46)\end{array}$ & $\begin{array}{l}23(38) \\
12(20) \\
26(43)\end{array}$ & \\
\hline Female, $n(\%)$ & $38(63)$ & $31(52)$ & 0.26 & $39(64)$ & $29(48)$ & 0.11 \\
\hline Non-Hispanic white, $n /$ total (\%) & $30 / 57(53)$ & $34 / 59$ (58) & $>0.99$ & $30 / 57(53)$ & $36 / 61(59)$ & 0.56 \\
\hline Baseline PCPC score $=1$ or $2, n(\%)$ & $55(92)$ & $50(83)$ & 0.23 & $56(92)$ & $50(82)$ & 0.18 \\
\hline Baseline POPC score $=1$ or $2, n(\%)$ & $55(92)$ & $48(80)$ & 0.09 & $56(92)$ & $48(79)$ & 0.08 \\
\hline PRISM III-12 score, median (IQR) & $12(4-21.5)$ & $11(5-17)$ & $>0.99$ & $12(4-21)$ & $10(3-14)$ & 0.06 \\
\hline $\begin{array}{l}\text { Risk of mortality based on PRISM III-12 } \\
\text { score, median (IQR) }\end{array}$ & $13.0(1.5-42.6)$ & $7.7(1.8-31.0)$ & 0.70 & $13.1(1.7-42.6)$ & $6.1(1.7-19.2)$ & 0.15 \\
\hline \multicolumn{7}{|l|}{ Primary diagnosis, $n(\%)$} \\
\hline $\begin{array}{l}\text { Aspiration pneumonia, bronchiolitis, } \\
\text { asthma }\end{array}$ & $15(25)$ & $15(25)$ & $>0.99$ & $15(25)$ & $16(26)$ & $>0.99$ \\
\hline Pneumonia & $27(45)$ & $27(45)$ & $>0.99$ & $28(46)$ & $31(51)$ & 0.73 \\
\hline Sepsis & $14(23)$ & $14(23)$ & $>0.99$ & $14(23)$ & $10(16)$ & 0.48 \\
\hline Other ${ }^{\dagger}$ & $4(7)$ & $4(7)$ & $>0.99$ & $4(7)$ & $4(7)$ & $>0.99$ \\
\hline $\begin{array}{l}\text { Number of organ dysfunctions on } \\
\text { Day } 0 \text { or } 1, \text { median (IQR) }\end{array}$ & $3(2-4)$ & $3(2-3)$ & 0.65 & $3(2-4)$ & $3(2-3)$ & 0.38 \\
\hline $\begin{array}{l}\text { PARDS based on worst OI or OSI on Day } \\
0 \text { or } 1, n(\%)^{\ddagger}\end{array}$ & & & 0.34 & & & 0.51 \\
\hline At risk $(\mathrm{OI}<4.0$ or $\mathrm{OSI}<5.0)$ & $0(0)$ & $0(0)$ & & $0(0)$ & $1(2)$ & \\
\hline Mild $(\mathrm{OI}=4.0-7.9$ or $\mathrm{OSI}=5.0-7.4)$ & $0(0)$ & $1(2)$ & & $0(0)$ & $1(2)$ & \\
\hline $\begin{array}{l}\text { Moderate }(\mathrm{OI}=8.0-16.0 \text { or } \mathrm{OSI}= \\
7.5-12.3)\end{array}$ & $4(7)$ & $7(12)$ & & $4(7)$ & $5(8)$ & \\
\hline $\begin{array}{l}\text { Severe }(\mathrm{OI}>16.0 \text { or OSI }>12.3) \\
\text { Any past medical history, } n(\%)\end{array}$ & $56(93)$ & $52(87)$ & & $57(93)$ & $54(89)$ & \\
\hline $\begin{array}{l}\text { Prematurity (<36 wk postmenstrual } \\
\text { age) }\end{array}$ & $7(12)$ & $14(23)$ & 0.12 & $8(13)$ & $6(10)$ & 0.79 \\
\hline $\begin{array}{l}\text { Asthma (prescribed bronchodilators or } \\
\text { steroids) }\end{array}$ & $6(10)$ & $7(12)$ & $>0.99$ & $7(11)$ & $10(16)$ & 0.58 \\
\hline $\begin{array}{l}\text { Seizure disorder (prescribed } \\
\text { anticonvulsants) }\end{array}$ & $3(5)$ & $5(8)$ & 0.73 & $3(5)$ & $8(13)$ & 0.23 \\
\hline $\begin{array}{l}\text { Neurologic/neuromuscular disorder } \\
\text { putting patient at risk of aspiration }\end{array}$ & $1(2)$ & $7(12)$ & 0.07 & $1(2)$ & $2(3)$ & $>0.99$ \\
\hline Cancer (current or previous diagnosis) & $8(13)$ & $9(15)$ & $>0.99$ & $8(13)$ & $9(15)$ & $>0.99$ \\
\hline Known chromosomal abnormality & $2(3)$ & 7 (12) & 0.06 & $2(3)$ & $4(7)$ & 0.69 \\
\hline $\begin{array}{l}\text { Sedation protocol group (vs. usual care), } \\
n(\%)\end{array}$ & $29(48)$ & $31(52)$ & 0.86 & $29(48)$ & $28(46)$ & $>0.99$ \\
\hline Ever used HFOV, $n(\%)$ & $33(55)$ & $34(57)$ & $>0.99$ & $34(56)$ & $35(57)$ & $>0.99$ \\
\hline OI before matching, median (IQR) & $43.7(31.0-63.1)$ & $44.4(31.2-56.4)$ & 0.05 & $43.9(31.7-63.5)$ & $42.9(36.1-51.0)$ & 0.44 \\
\hline Ol before matching, $n(\%)$ & & & $>0.99$ & & & 0.44 \\
\hline$<20$ & $5(8)$ & $5(8)$ & & $5(8)$ & $2(3)$ & \\
\hline $20-29.9$ & 9 (15) & 9 (15) & & 9 (15) & $6(10)$ & \\
\hline $30-39.9$ & $12(20)$ & $12(20)$ & & $12(20)$ & $15(25)$ & \\
\hline$\geqslant 40$ & $34(57)$ & $34(57)$ & & $35(57)$ & $38(62)$ & \\
\hline $\begin{array}{l}\text { Length of mechanical ventilation on } \\
\text { day of matching, } d \text {, median (IQR) }\end{array}$ & $2.5(1-6)$ & $1.5(1-5)$ & 0.02 & $3(1-6)$ & $3(1-5)$ & 0.56 \\
\hline $\mathrm{Fl}_{\mathrm{O}_{2}}=100 \%$ before matching, $n(\%)$ & $46(77)$ & $32(53)$ & 0.004 & $47(77)$ & $47(77)$ & $>0.99$ \\
\hline
\end{tabular}

Definition of abbreviations: $\mathrm{ECMO}=$ extracorporeal membrane oxygenation; HFOV = high-frequency oscillatory ventilation; IQR = interquartile range; $\mathrm{Ol}=$ oxygenation index; OSI = oxygen saturation index; PARDS = pediatric acute respiratory distress syndrome; PCPC = Pediatric Cerebral Performance Category; PICU = pediatric ICU; POPC = Pediatric Overall Performance Category; PRISM III-12= Pediatric Risk of Mortality III score from first $12 \mathrm{~h}$ in the $\mathrm{PICU} ; \mathrm{Sp}_{\mathrm{O}_{2}}=$ oxygen saturation as measured by pulse oximetry.

${ }^{*} P$ values for comparison between matched pairs were calculated using exact sign tests for continuous and ordinal variables and exact conditional maximum likelihood estimation for binary variables.

${ }^{\dagger}$ Other primary diagnoses include acute chest syndrome/sickle cell disease, pertussis, pulmonary edema, pulmonary hemorrhage, and thoracic trauma. ${ }^{\ddagger} \mathrm{OI}$ was calculated as $\left(\mathrm{Fl}_{\mathrm{O}_{2}} \times\right.$ mean airway pressure) $/ \mathrm{Pa}_{\mathrm{O}_{2}} \times 100$. When an arterial blood gas measurement was not available, Sp $\mathrm{O}_{2}$ was used to estimate $\mathrm{Pa}_{\mathrm{O}_{2}}$ in order to calculate $\mathrm{OSI}\left[\left(\mathrm{FI}_{\mathrm{O}_{2}} \times\right.\right.$ mean airway pressure $\left.) / \mathrm{Sp}_{\mathrm{O}_{2}} \times 100\right]$. Lower scores reflect better oxygenation. 


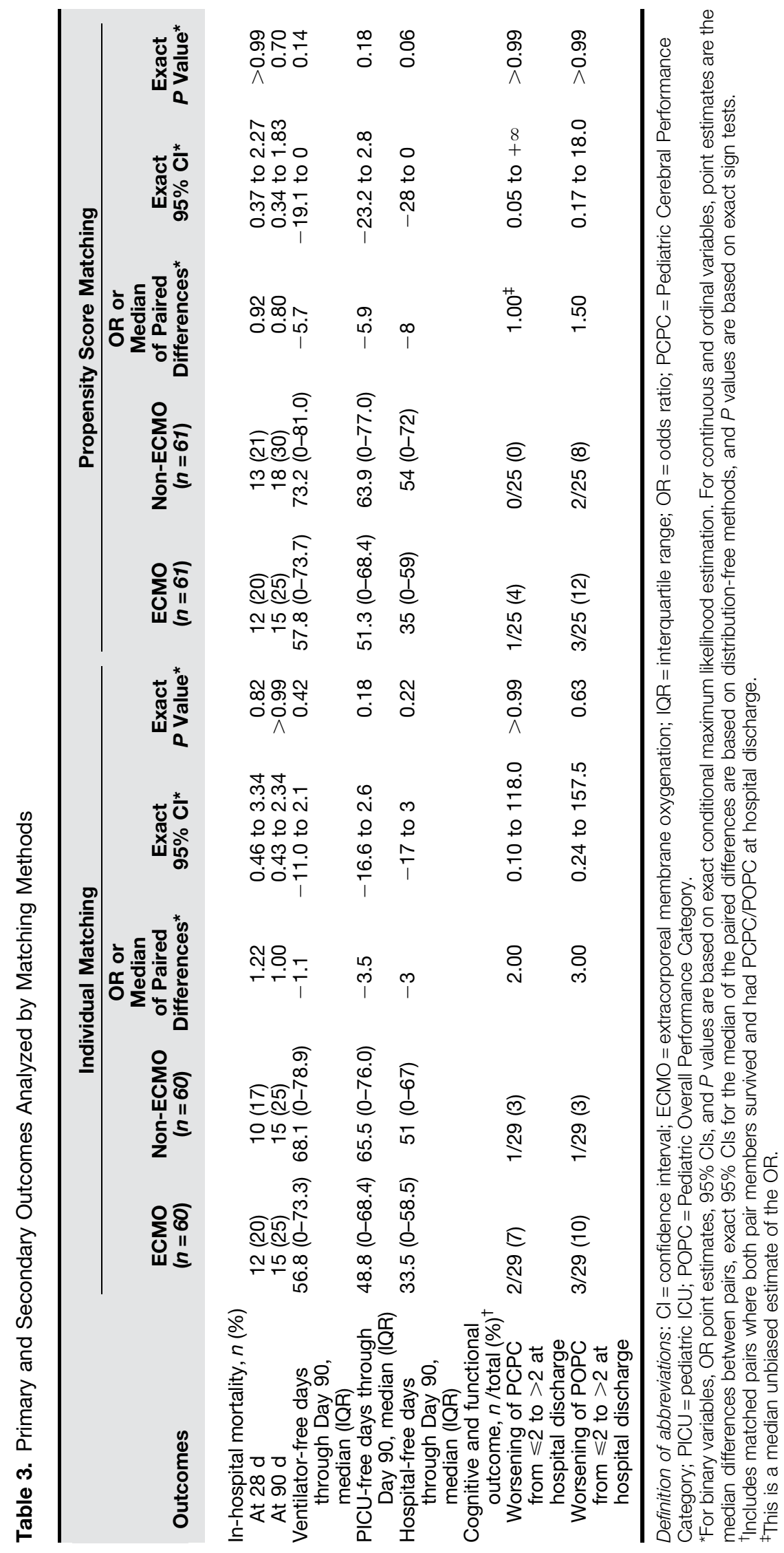


The absence of statistical significance may reflect the absence of a true difference in mortality or an absence of power to detect a difference. This distinction is significant, because a true 5 or $10 \%$ absolute risk reduction in mortality would be clinically important.

Before matching, ECMO-supported patients with ARDS and non-ECMOsupported patients with ARDS were different. ECMO-supported patients more commonly had a normal baseline functional status as measured by POPC and PCPC. ECMO-supported patients also had a higher admission risk of mortality, a higher number of organ system failures, and a higher use of HFOV than non-ECMOsupported patients who developed severe ARDS. After propensity score matching, none of these differences remained statistically significant. Although it is worth acknowledging that even after propensity matching, the admission risk of mortality was $13.1 \%$ for ECMO-supported patients versus $6.1 \%$ for non-ECMO-supported patients, and although this is not a statistically significantly difference, it may be that our study was underpowered to detect a difference. Like all observational studies, our pair-matched analysis of the RESTORE data is as accurate as its ability to balance measured and unmeasured covariates that may confound the outcome of interest (34).

There was variability in ECMO and ventilation practices among all patients in the RESTORE trial $(26,35)$. At present, there are no evidence-based guidelines for ECMO support in pediatric respiratory failure $(19,36)$. At the time the RESTORE trial was conducted, there were no consensus guidelines or adequately powered pediatric clinical trials in PARDS that identified best practices for mechanical ventilator support in PARDS $(29,37)$. This variability in practice can be a symptom of the lack of evidence guiding practice (38).

The 61 patients receiving ECMO cared for in this study had a similar pre-ECMO severity of illness to patients reported in the Extracorporeal Life Support Organization (ELSO) Registry between 2009 and 2014 (39). In the ELSO Registry, patients were placed on ECMO at an OI of 44 (IQR, 30-60) and after 2.0 days (IQR, 0.6-6.2 d) of mechanical ventilation, which is similar to the findings in this study (Table 2) (39). There was also a similar pre-ECMO use of $\mathrm{HFOV}$ ( $44 \%$ in ELSO vs. $55 \%$ in this study) (39).
Regarding length of clinical care, the hospital-, PICU-, and ventilator-free days are not statistically different between ECMO-supported and non-ECMOsupported children. However, in a post hoc analysis, when the analysis is restricted to survivors, the PICU and hospital length of stay are significantly longer for the ECMOsupported compared with non-ECMOsupported children. In the a priori specified comparison among propensity scorematched patients, 90-day hospital-free days was 35 days (IQR, 0-59 d) for the ECMO-supported versus 54 days (0-72 d) for the non-ECMO-supported patients $(P=0.06)$. The absence of a difference between ECMO-supported and nonECMO-supported patients may reflect a true absence in difference, insufficient power, or a limitation of our model to adjust for underlying differences in the two groups. Notably, the CESAR (Conventional Ventilation or ECMO for Severe Adult Respiratory Failure) trial found that adults randomized to be referred to an ECMO center had a longer ICU and hospital length of stay (14). Alternatively, a trial randomizing adults to receive pumpless arteriovenous extracorporeal $\mathrm{CO}_{2}$ elimination versus a strategy of low tidal volume conventional mechanical ventilation $(\sim 6 \mathrm{ml} / \mathrm{kg})$ without arteriovenous extracorporeal $\mathrm{CO}_{2}$ elimination did not replicate these differences (15).

In our secondary analysis of data from the RESTORE clinical trial, we found a $25 \%$ mortality rate in ECMO-supported patients with acute respiratory failure compared with a $40 \%$ mortality rate for a similar cohort in the ELSO Registry (39). It is also lower than the reported mortality for severe ARDS with an OI greater than twenty (43-56\%) (40). Lower mortality rates have also been reported in adult randomized controlled trials of ARDS compared with observational studies. The lower mortality rate in randomized controlled trials is believed to stem from specialized center care, scrutiny of care, and exclusion of patients with poor prognosis (41). The lower mortality rate may also reflect uncaptured mortality after 90 days but before hospital discharge (42).

We found no difference between ECMO-supported and non-ECMOsupported patients in the change in functional outcomes. By contrast, the neonatal randomized controlled trial on
ECMO versus conventional management showed improved rates of cognitively intact survival among the ECMOsupported group (11). In our study, we considered the change in neurocognitive status among survivors using the somewhat broad categories of the PCPC, which is slightly different and may partially account for the different finding. Alternatively, some have hypothesized that ECMO may result in worse neurocognitive survival, but our study results do not support that hypothesis for ECMO-supported children with acute respiratory failure (43).

After the publication of the new PARDS operational definition and practice guidelines as well as the success of several large clinical trials in pediatric critical care, the field is poised to conduct a randomized controlled trial of ECMO versus ventilation therapy alone using patient-level randomization $(25,29,44,45)$. In such a trial, we would recommend enrolling patients who developed severe PARDS (OI $>16$ ) within 48 hours of intubation to ensure patients in both arms receive similar protocolized mechanical ventilation (46). However, patients would only be randomized to ECMO or continued conventional management once they sustained an oxygenation index of 40 or greater for at least 4 hours (11). Limiting patient enrollment to children who develop PARDS in the first 48 hours seems plausible, because 802 patients enrolled in the clinical trial RESTORE had severe PARDS within 24 hours of study enrollment (25). In the absence of equipoise, an alternative approach would be to randomize patients to early versus delayed ECMO on the basis of OI thresholds. This study design has been done in early versus delayed renal replacement therapy and in a pilot study among neonates receiving ECMO for respiratory failure $(47,48)$.

This study leverages reliably collected data, a large cohort of patients with ARDS, and rigorous statistical technique to compare outcomes among ECMOsupported and non-ECMO-supported patient populations. We did not find a difference in patient outcomes. In the past, it has been proposed that a study of ECMO is unethical, because children who would have survived with ECMO will die without it $(49,50)$. This study challenges that notion, and we urge a careful consideration of the best way to perform ethical rigorous research aimed at identifying the best way 
to support children with severe acute respiratory failure.

\section{Conclusions}

In children with severe ARDS, our results do not demonstrate that ECMO-supported children have superior outcomes compared with non-ECMO-supported children. A rigorously performed, randomized controlled clinical trial of ECMO in severe PARDS should be performed to provide definitive answers to this long-standing conundrum in pediatric critical care.

Author disclosures are available with the text of this article at www.atsjournals. org.

\section{References}

1. Bartlett RH, Gazzaniga AB, Jefferies MR, Huxtable RF, Haiduc NJ, Fong SW. Extracorporeal membrane oxygenation (ECMO) cardiopulmonary support in infancy. Trans Am Soc Artif Intern Organs 1976;22:80-93.

2. Barbaro RP, Boonstra PS, Moler FW, Davis MM, Prosser LA. Hospitallevel variation in inpatient cost among children receiving extracorporeal membrane oxygenation. Perfusion 2017;32:538-546.

3. Barbaro RP, Paden ML, Guner YS, Raman L, Ryerson LM, Alexander P, et al.; ELSO member centers. Pediatric Extracorporeal Life Support Organization Registry international report 2016. ASAIO J 2017;63: 456-463.

4. Colvin M, Smith JM, Skeans MA, Edwards LB, Uccellini K, Snyder JJ, et al. OPTN/SRTR 2015 annual data report: heart. Am J Transplant 2017;17:286-356.

5. Hart A, Smith JM, Skeans MA, Gustafson SK, Stewart DE, Cherikh WS, et al. OPTN/SRTR 2015 annual data report: kidney. Am J Transplant 2017;17:21-116.

6. Kim WR, Lake JR, Smith JM, Skeans MA, Schladt DP, Edwards EB, et al. OPTN/SRTR 2015 annual data report: liver. Am J Transplant 2017;17: 174-251.

7. Faraoni D, Nasr VG, DiNardo JA, Thiagarajan RR. Hospital costs for neonates and children supported with extracorporeal membrane oxygenation. J Pediatr 2016;169:69-75.e1.

8. Bartlett RH, Roloff DW, Cornell RG, Andrews AF, Dillon PW, Zwischenberger JB. Extracorporeal circulation in neonatal respiratory failure: a prospective randomized study. Pediatrics 1985;76:479-487.

9. O'Rourke PP, Crone RK, Vacanti JP, Ware JH, Lillehei CW, Parad RB, et al. Extracorporeal membrane oxygenation and conventional medical therapy in neonates with persistent pulmonary hypertension of the newborn: a prospective randomized study. Pediatrics 1989;84: 957-963.

10. Bifano EM, Hakanson DO, Hingre RV, Gross SJ. Prospective randomized controlled trial of conventional treatment or transport for ECMO in infants with persistent pulmonary hypertension (PPHN) [abstract]. Pediatr Res 1992;31:196A.

11. UK Collaborative ECMO Trail Group. UK collaborative randomised trial of neonatal extracorporeal membrane oxygenation. Lancet 1996; 348:75-82.

12. Zapol WM, Snider MT, Hill JD, Fallat RJ, Bartlett RH, Edmunds LH, et al. Extracorporeal membrane oxygenation in severe acute respiratory failure: a randomized prospective study. JAMA 1979;242: 2193-2196.

13. Morris AH, Wallace CJ, Menlove RL, Clemmer TP, Orme JF Jr, Weaver LK, et al. Randomized clinical trial of pressure-controlled inverse ratio ventilation and extracorporeal $\mathrm{CO} 2$ removal for adult respiratory distress syndrome. Am J Respir Crit Care Med 1994;149:295-305.

14. Peek GJ, Mugford M, Tiruvoipati R, Wilson A, Allen E, Thalanany MM, et al.; CESAR trial collaboration. Efficacy and economic assessment of conventional ventilatory support versus extracorporeal membrane oxygenation for severe adult respiratory failure (CESAR): a multicentre randomised controlled trial. Lancet 2009;374:1351-1363.

15. Bein T, Weber-Carstens S, Goldmann A, Müller T, Staudinger T, Brederlau J, et al. Lower tidal volume strategy $(\approx 3 \mathrm{ml} / \mathrm{kg})$ combined with extracorporeal $\mathrm{CO} 2$ removal versus 'conventional' protective ventilation $(6 \mathrm{ml} / \mathrm{kg})$ in severe ARDS: the prospective randomized Xtravent-study. Intensive Care Med 2013;39:847-856.

16. Mugford M, Elbourne D, Field D. Extracorporeal membrane oxygenation for severe respiratory failure in newborn infants. Cochrane Database Syst Rev 2008;3:CD001340.
17. Tramm R, llic D, Davies AR, Pellegrino VA, Romero L, Hodgson C. Extracorporeal membrane oxygenation for critically ill adults. Cochrane Database Syst Rev 2015;1:CD010381.

18. Rehder KJ, Turner DA, Bonadonna D, Walczak RJ, Rudder RJ, Cheifetz IM. Technological advances in extracorporeal membrane oxygenation for respiratory failure. Expert Rev Respir Med 2012;6:377-384.

19. Combes A, Brodie D, Chen YS, Fan E, Henriques JPS, Hodgson C, et al. The ICM research agenda on extracorporeal life support. Intensive Care Med 2017:43:1306-1318.

20. Guérin C, Reignier J, Richard JC, Beuret P, Gacouin A, Boulain T, et al.; PROSEVA Study Group. Prone positioning in severe acute respiratory distress syndrome. N Engl J Med 2013;368:2159-2168.

21. Ferguson ND, Cook DJ, Guyatt GH, Mehta S, Hand L, Austin P, et al.; OSCILLATE Trial Investigators; Canadian Critical Care Trials Group. High-frequency oscillation in early acute respiratory distress syndrome. N Engl J Med 2013;368:795-805.

22. Papazian L, Forel JM, Gacouin A, Penot-Ragon C, Perrin G, Loundou A, et al.; ACURASYS Study Investigators. Neuromuscular blockers in early acute respiratory distress syndrome. N Engl J Med 2010;363: $1107-1116$.

23. Amato MB, Meade MO, Slutsky AS, Brochard L, Costa EL, Schoenfeld DA et al. Driving pressure and survival in the acute respiratory distress syndrome. N Engl J Med 2015;372:747-755.

24. Barbaro RP, Odetola FO, Kidwell KM, Paden ML, Bartlett RH, Davis MM, et al. Association of hospital-level volume of extracorporeal membrane oxygenation cases and mortality: analysis of the extracorporeal life support organization registry. Am J Respir Crit Care Med 2015;191:894-901.

25. Curley MA, Wypij D, Watson RS, Grant MJ, Asaro LA, Cheifetz IM, et al.; RESTORE Study Investigators and the Pediatric Acute Lung Injury and Sepsis Investigators Network. Protocolized sedation vs usual care in pediatric patients mechanically ventilated for acute respiratory failure: a randomized clinical trial. JAMA 2015;313:379-389.

26. Schneider JB, Sweberg T, Asaro LA, Kirby A, Wypij D, Thiagarajan RR, et al.; Randomized Evaluation of Sedation Titration for Respiratory Failure (RESTORE) Study Investigators. Sedation management in children supported on extracorporeal membrane oxygenation for acute respiratory failure. Crit Care Med 2017;45:e1001-e1010.

27. Zabrocki LA, Brogan TV, Statler KD, Poss WB, Rollins MD, Bratton SL. Extracorporeal membrane oxygenation for pediatric respiratory failure: survival and predictors of mortality. Crit Care Med 2011;39: 364-370.

28. Fiser DH, Long N, Roberson PK, Hefley G, Zolten K, Brodie-Fowler M. Relationship of pediatric overall performance category and pediatric cerebral performance category scores at pediatric intensive care unit discharge with outcome measures collected at hospital discharge and 1- and 6-month follow-up assessments. Crit Care Med 2000;28: 2616-2620.

29. Pediatric Acute Lung Injury Consensus Conference Group. Pediatric acute respiratory distress syndrome: consensus recommendations from the Pediatric Acute Lung Injury Consensus Conference. Pediatr Crit Care Med 2015;16:428-439.

30. Pham T, Combes A, Rozé H, Chevret S, Mercat A, Roch A, et al.; REVA Research Network. Extracorporeal membrane oxygenation for pandemic influenza $\mathrm{A}(\mathrm{H} 1 \mathrm{~N} 1)$-induced acute respiratory distress syndrome: a cohort study and propensity-matched analysis. Am J Respir Crit Care Med 2013;187:276-285.

31. Noah MA, Peek GJ, Finney SJ, Griffiths MJ, Harrison DA, Grieve R, et al. Referral to an extracorporeal membrane oxygenation center and mortality among patients with severe 2009 influenza $A(H 1 N 1)$. JAMA 2011;306:1659-1668. 
32. Rehder KJ, Turner DA, Cheifetz IM. Extracorporeal membrane oxygenation for neonatal and pediatric respiratory failure: an evidence-based review of the past decade (2002-2012). Pediatr Crit Care Med 2013;14:851-861.

33. Kuo KW, Barbaro RP, Gadepalli SK, Davis MM, Bartlett RH, Odetola FO. Should extracorporeal membrane oxygenation be offered? An international survey. J Pediatr 2017;182:107-113.

34. Guo S, Fraser M. Propensity score analysis: statistical methods and applications (advanced quantitative techniques in the social sciences). Thousand Oaks, CA: Sage Publications; 2010.

35. Bateman ST, Borasino S, Asaro LA, Cheifetz IM, Diane S, Wypij D, et al.; RESTORE Study Investigators. Early high-frequency oscillatory ventilation in pediatric acute respiratory failure: a propensity score analysis. Am J Respir Crit Care Med 2016;193:495-503.

36. Dalton HJ, Macrae DJ; Pediatric Acute Lung Injury Consensus Conference Group. Extracorporeal support in children with pediatric acute respiratory distress syndrome: proceedings from the Pediatric Acute Lung Injury Consensus Conference. Pediatr Crit Care Med 2015;16:S111-S117.

37. Rimensberger PC, Cheifetz IM; Pediatric Acute Lung Injury Consensus Conference Group. Ventilatory support in children with pediatric acute respiratory distress syndrome: proceedings from the Pediatric Acute Lung Injury Consensus Conference. Pediatr Crit Care Med 2015;16:S51-S60.

38. Keren R, Luan X, Localio R, Hall M, McLeod L, Dai D, et al.; Pediatric Research in Inpatient Settings (PRIS) Network. Prioritization of comparative effectiveness research topics in hospital pediatrics. Arch Pediatr Adolesc Med 2012;166:1155-1164.

39. Barbaro RP, Boonstra PS, Paden ML, Roberts LA, Annich GM, Bartlett RH, et al. Development and validation of the pediatric risk estimate score for children using extracorporeal respiratory support (PedRESCUERS). Intensive Care Med 2016;42:879-888.

40. Khemani RG, Smith LS, Zimmerman JJ, Erickson S; Pediatric Acute Lung Injury Consensus Conference Group. Pediatric acute respiratory distress syndrome: definition, incidence, and epidemiology: proceedings from the Pediatric Acute Lung Injury Consensus Conference. Pediatr Crit Care Med 2015;16:S23-S40.
41. Phua J, Badia JR, Adhikari NK, Friedrich JO, Fowler RA, Singh JM, et al. Has mortality from acute respiratory distress syndrome decreased over time? A systematic review. Am J Respir Crit Care Med 2009; 179:220-227.

42. Máca J, Jor O, Holub M, Sklienka P, Burša F, Burda M, et al. Past and present ARDS mortality rates: a systematic review. Respir Care 2017; 62:113-122.

43. Cashen K, Reeder R, Dalton HJ, Berg RA, Shanley TP, Newth CJL, et al.; Eunice Kennedy Shriver National Institute of Child Health and Human Development Collaborative Pediatric Critical Care Research Network (CPCCRN). Functional status of neonatal and pediatric patients after extracorporeal membrane oxygenation. Pediatr Crit Care Med 2017;18:561-570.

44. Moler FW, Silverstein FS, Holubkov R, Slomine BS, Christensen JR, Nadkarni VM, et al.; THAPCA Trial Investigators. Therapeutic hypothermia after in-hospital cardiac arrest in children. N Engl J Med 2017;376:318-329.

45. Agus MS, Wypij D, Hirshberg EL, Srinivasan V, Faustino EV, Luckett PM, et al.; HALF-PINT Study Investigators and the PALISI Network. Tight glycemic control in critically ill children. N Engl J Med 2017;376: 729-741.

46. Bein T, Graf B, Weber-Carstens S. Ventilatory support versus ECMO for severe adult respiratory failure. Lancet 2010;375:549-550, author reply 551 .

47. Gaudry S, Hajage D, Schortgen F, Martin-Lefevre L, Pons B, Boulet E, et al.; AKIKI Study Group. Initiation strategies for renalreplacement therapy in the intensive care unit. $N$ Engl $\mathrm{J}$ Med 2016;375:122-133.

48. Schumacher RE, Roloff DW, Chapman R, Snedecor S, Bartlett RH. Extracorporeal membrane oxygenation in term newborns: a prospective cost-benefit analysis. ASAIO J 1993;39:873-879.

49. Bluhm R. The epistemology and ethics of chronic disease research: further lessons from ECMO. Theor Med Bioeth 2010; 31:107-122.

50. Lantos JD, Frader J. Extracorporeal membrane oxygenation and the ethics of clinical research in pediatrics. N Engl J Med 1990;323: 409-413. 